\title{
A COOPERAÇÃO ENTRE \\ OS STAKEHOLDERS E O \\ DESENVOLVIMENTO TURÍSTICO DOS TERRITÓRIOS RURAIS - O CASO DA SUB-REGIÃO DO BAIXO ALENTEJO (ALENTEJO - PORTUGAL)
}

COOPERATION BETWEEN STAKEHOLDERS AND TOURISM DEVELOPMENT OF THE RURAL TERRITORIES - THE CASE OF THE BAIXO ALENTEJO SUB-REGION (ALENTEJO - PORTUGAL)

LA COOPERACIÓN ENTRE LOS STAKEHOLDERS Y EL DESARROLLO TURÍSTICO DE LOS TERRITORIOS RURALES - EL CASO DE LA SUBREGIÓN DEL BAIXO ALENTEJO (ALENTEJO - PORTUGAL)

\section{Marta Isabel Casteleiro Amaral}

Professora Adjunta do Departamento de Ciências Empresariais do Instituto Politécnico de Beja

Docente na Licenciatura em Turismo marta.amaral@ipbeja.pt

Doutora em Turismo/Universidade de Évora Mestre em Sociologia (Recursos Humanos e Desenvolvimento Sustentável)/ Universidade de Évora Licenciada em Sociologia do Trabalho/ISCSP - UTL

Data de Submissão: 10/09/2015

Data de Aprovação: 12/11/2015

RESUMO: Este artigo, que resultou de uma investigação de Doutorado, tem como objetivo analisar a importância da cooperação entre os stakeholders para o desenvolvimento turístico dos territórios rurais, numa perspectiva de sustentabilidade. A cooperação entre os atores chave do setor turístico 
representa uma mais valia, no sentido de promover os destinos turísticos rurais. Baseando-se numa investigação empírica de caráter quantitativo, procurou-se, com um questionário estruturado, aplicado via e-mail e correio tradicional aos stakeholders do setor público, setor privado e associativo do turismo, avaliar a percepção daqueles agentes, sobre as medidas e as áreas de atuação prioritária em termos de cooperação de modo a contribuir para o desenvolvimento turístico de uma subregião de Portugal, o Baixo Alentejo, tipicamente rural. Concluiu-se que os agentes consideram importante haver uma cooperação intersetorial, pois: fortalece o turismo, contribuindo para a revitalização econômica e social dos territórios rurais; aumenta a competitividade empresarial; permite as trocas de recursos onde se inclui o capital, o conhecimento; e reforça a legitimidade das políticas de turismo.

PALAVRAS-CHAVE: Turismo. Desenvolvimento Sustentável. Cooperação entre Atores.

ABSTRACT: This article, which is the result of research carried out for a $\mathrm{PhD}$, analyzes the importance of cooperation among stakeholders for the tourism development of rural areas, from a perspective of sustainability. Cooperation between key players in the tourism sector is an asset for promoting rural tourist destinations. Based on an empirical, quantitative investigation, we sought to understand the perceptions of the agents on the measures and the key areas of investment in terms of cooperation, in order to contribute to tourism development of the Baixo Alentejo, a typically rural sub-region of Portugal. To collect this information, a structured questionnaire was sent by email and by post to stakeholders in the public, private and voluntary tourism sectors. It was concluded that agents consider cooperation between sectors to be important because; it strengthens tourism; it contributes to the economic and social revitalization of rural areas; it increases business competitiveness; it allows the exchange of resources, including capital and knowledge; and it reinforces the legitimacy of tourism policies.

KEY WORDS: Tourism. Sustainable Development. Stakeholder Cooperation.

RESUMEN: Este artículo, que resultó de una investigación de Doctorado, tiene como objetivo analizar la importancia de la cooperación entre los stakeholders para el desarrollo turístico de los territorios rurales desde el punto de vista de la sostenibilidad. La cooperación entre los actores clave del sector turístico representa una plusvalía, en el sentido de promover los destinos turísticos rurales. Basándose en una investigación empírica de carácter cuantitativo, se intentó evaluar la percepción de los stakeholders del sector público, sector privado y asociativo del turismo a través de un cuestionario estructurado, aplicado vía e-mail y correo tradicional, sobre las medidas y las áreas de actuación prioritaria en términos de cooperación, a fin de contribuir para el desarrollo turístico de una subregión típicamente rural de Portugal, el Baixo Alentejo. Se concluyó que los agentes consideran importante que haya una cooperación intersectorial, pues esta fortalece el turismo, contribuyendo a la revitalización económica y social de los territorios rurales, aumenta la competitividad empresarial, permite el intercambio de recursos en los que se incluye el capital y el conocimiento, y refuerza la legitimidad de las políticas de turismo.

PALABRAS CLAVE: Turismo. Desarrollo Sostenible. Cooperación entre Stakeholders. 


\section{INTRODUÇÃO}

partir das grandes reflexões sobre a necessidade da sustentabilidade
no turismo, a observação das práticas da cooperação e da
colaboração entre atores adquire natureza de problema dominante (JAMAL; GETZ, 1995; PARKER, 2000). Os principais estudos no domínio do turismo sustentável cedo apresentaram como fundamento os benefícios que os vários atores podem obter ao colaborarem em conjunto, procurando construir, assim, o consenso a propósito das políticas públicas (BRAMWELL; SHARMAN, 1999). Os cientistas sociais que investigam o turismo como fenômeno das sociedades modernas consideram que um turismo bem-sucedido e numa perspectiva de sustentabilidade resulta, essencialmente, da cooperação que se estabelece entre os vários atores ou agentes que, direta ou indiretamente, intervêm no processo de desenvolvimento turístico. De fato, a cooperação é bem-vista como estratégia de fortalecimento do turismo (HALL, 1999) e, neste sentido, as interações aos vários níveis revelam-se cruciais (GOELDNER; RITCHIE, 2009). A política, o planejamento e o desenvolvimento sustentável pressupõem que sejam conduzidos dentro de uma estrutura organizacional, conjunta, colaborante e cooperativa, resultante de uma interação mútua entre o setor público e o setor privado, o que é verdadeiramente relevante porque são estes grupos de atores que controlam e chegam a operacionalizar um grande número de facilidades turísticas. De fato, a não consideração dessa realidade leva a um processo de desenvolvimento antagônico e desarticulado (GOELDNER; RITCHIE, 2009). A problemática da cooperação nos destinos turísticos tem tido, nos últimos anos, uma grande atenção acadêmica e industrial, com o reconhecimento crescente dos benefícios tangíveis e intangíveis que resultam dessa mesma cooperação entre os atores sociais para o desenvolvimento do turismo (ELIAS, 2014; ZHANG; YAN; LO, 2009). Numa perspectiva de desenvolvimento turístico sustentável requer-se, cada vez mais, uma maior cooperação e colaboração entre atores do turismo, ao nível regional e local (JAMAL; GETZ, 1995; KIMBU; NGOASONG, 2013). Aceitando o turismo como um setor que proporciona o desenvolvimento endógeno e local, e num quadro de grandes mudanças que vêm marcando a estrutura econômica e social de inúmeras regiões (especialmente 
as rurais, no interior), as oportunidades de desenvolvimento das atividades turísticas aparecem como denominador comum de diversas estratégias de desenvolvimento (SILVA; SILVA, 2003). Importa, por esse fato, tecer algumas considerações sobre esta relação, sobretudo no contexto do desenvolvimento de destinos em regiões rurais, que se justifica pelo fato do estudo que está na base deste artigo, geograficamente, ter incidido numa região do interior de Portugal, e tipicamente rural. Esta é, pois, a grande premissa da investigação em que se baseia o presente artigo, que teve como principal problemática abordar a necessidade de cooperação entre os stakeholders, públicos, privados e associativos, para o desenvolvimento turístico de uma sub-região rural no sul de Portugal: o Baixo Alentejo (Alentejo).

Neste sentido, o estudo procurou analisar a percepção dos atores do turismo sobre a importância que atribuem ao estabelecimento de relações de cooperação, considerando fundamentalmente as suas vantagens e suas desvantagens no desenvolvimento turístico e na competitividade da região. A pesquisa teve ainda como objetivo compreender a percepção dos agentes turísticos inquiridos sobre as áreas prioritárias em que os atores podem cooperar, para promover o desenvolvimento turístico da sub-região, e as principais medidas a tomar no sentido de aumentar a competitividade deste destino rural.

\section{O TURISMO E O DESENVOLVIMENTO DOS TERRITÓRIOS RURAIS}

Num contexto de uma grande urbanização, com uma elevada concentração das populações e das atividades econômicas, tem havido tendencialmente uma disseminação geográfica das áreas rurais. Apesar de estas áreas apresentarem uma grande diversidade, a maior parte é caraterizada pelo êxodo, o envelhecimento e o abandono progressivo das atividades tradicionais relacionadas com o setor primário (DINIS, 2011). Nesse sentido, a promoção do desenvolvimento rural e das áreas periféricas desperta o interesse no rejuvenescimento desses territórios, tendo por meio o turismo. O turismo rural é, deste modo, considerado como uma ferramenta útil para o desenvolvimento (KASTENHOLZ, 2010; EURICO; OLIVEIRA, 2015), apesar de não ser realmente fácil equilibrar a procura e a otimização dos benefícios tanto para os turistas como para as áreas rurais que eles visitam 
(FOTIADIS, 2009). A realidade da atividade turística revela a preocupação em associar o turismo com o desenvolvimento, em particular nas regiões periféricas, rurais ou em vias de desenvolvimento, e justifica os vários recursos envolvidos e os investimentos efetuados pelas comunidades, governos e associações de desenvolvimento por todo o mundo. A ligação entre o turismo e o desenvolvimento é poderosa e o incentivo ao turismo, tanto nos países desenvolvidos como nos países em vias de desenvolvimento, deverá cumprir um conjunto de condições prévias corretas, numa combinação de atrações naturais, paisagísticas, históricas, arqueológicas, culturais e climáticas (McINTOSH et al., 2004; MASON, 2015), que constituem um "trunfo" dos meios rurais. Na realidade, o turismo é visto como um agente importante para a regeneração e o redesenvolvimento econômico de determinadas regiões rurais e isoladas graças aos elementos de atração que estas apresentam, constituindo um meio de sustento e diversificação das economias rurais e das sociedades (FOTIADIS, 2009; JACKSON; MURPHY, 2006; SHARPLEY; TELFER, 2002). Neste sentido, todos os esforços deverão ter como princípio o desenvolvimento de produtos inovadores e diferenciados, para o reforço das parcerias estratégicas e para a preservação do equilíbrio ambiental e a valorização do patrimônio cultural. Portanto, o sucesso da atividade turística assenta, claramente, nos recursos locais, quantitativos e qualitativos (RIBEIRO; VAREIRO, 2007; CARVALHO; LIMA; KASTENHOLZ, 2014).

Em Portugal, a atividade turística tem ganhado maior dimensão nas políticas de desenvolvimento ao nível local, fruto das preocupações relacionadas com o esgotamento dos modelos de localização espacial de diversas atividades produtivas, como a agricultura e a indústria extrativa. Mas esta não é a única razão. Acresce ainda o próprio dinamismo da procura turística, quer do ponto de vista quantitativo, quer do ponto de vista de uma permanente diversificação dos seus perfis e ainda a valorização por parte da mesma relativamente a produtos turísticos diferenciados, especialmente aqueles que estão associados às caraterísticas ambientais e culturais de base territorial (SILVA; SILVA, 2003). Portanto, o turismo deverá ser visto para além da sua dimensão econômica, agregando outras dimensões (social, cultural, ambiental, institucional), podendo tornar-se numa estratégia alternativa para um desenvolvimento mais sustentável, preservando e valorizando aspetos determinantes como as 
tradições e as relações sociais e permitindo racionalizar o uso dos recursos naturais e também gerando renda e aproveitando as capacidades humanas locais (SAMPAIO, 2003; PELLIN, 2005; SILVA; PERNA, 2002).

As atuais formas de turismo que surgem num contexto de desenvolvimento do meio rural estão associadas a algumas mudanças na própria sociedade, nomeadamente pelo aumento dos níveis de educação, pelo maior interesse pelo patrimônio natural e artificial e pelo desenvolvimento dos transportes e comunicação. Nestas circunstâncias, as áreas rurais dificilmente podem já ser consideradas totalmente remotas e isoladas e constituem meios privilegiados para a satisfação de necessidades cada vez mais prementes, inclusive em termos de saúde, estética e bem-estar (OECD, 1994).

Em muitos países, o desenvolvimento do turismo no meio rural tem vindo a ser alvo de uma grande preocupação, o que se revela em termos de assistência financeira direta por parte do setor público e do setor privado. A relação entre o turismo e o desenvolvimento local é notória, pois quando desenvolvido em espaços rurais o turismo é uma alternativa importante para fortalecer o território rural e, principalmente, para interiorizar a atividade turística, hoje ainda muito concentrada no litoral e, sobretudo, na época do verão (PELLIN, 2005). Neste contexto, é fulcral que "[...] as decisões sejam tomadas no âmbito local, que haja controlo dos processos de desenvolvimento por atores sociais locais, e que as comunidades locais se apropriem dos benefícios gerados" (PELLIN, 2005, p.41). Considerando as particularidades desta atividade econômica em que é o consumidor que procura o serviço, pode-se afirmar que o turismo tem forte impacto no desenvolvimento local e que "[...] nesta perspectiva, a atividade de turismo e o desenvolvimento local se fundem, quando as características regionais, sociais, culturais e ambientais são respeitadas" (CUNHA; CUNHA, 2005, p.3).

O turismo tem um papel importante nas regiões subdesenvolvidas em que a falta de "civilização moderna" pode constituir um fator de atração (KASTENHOLZ, 2002). No meio rural este setor traz oportunidades ao nível da criação de empregos e empreendimentos e pode ser visto como uma possibilidade de sustento econômico e uma alternativa às economias das regiões em que as atividades tradicionais foram perdendo importância sem capacidade de satisfazer 
as populações delas dependentes (SOUSA, 2006; SHARPLEY, 2005). Por fim, mas não menos importante, é uma excelente forma de recuperação e valorização do território, pois, ao depender da gestão do espaço local e rural para o seu sucesso, também contribui para a proteção do meio ambiente e para a conservação do patrimônio natural, histórico e cultural desse meio, estimulando a gestão e o uso sustentável do espaço local, beneficiando, prioritariamente, a população local, direta e indiretamente, envolvida nas atividades turísticas (CAMPANHOLA; SILVA, 1999). Esta perspectiva baseia-se no paradigma do desenvolvimento endógeno que surgiu na década de 70 e 80 do século passado e que tinha como princípio uma orientação de "baixo para cima", procurando essencialmente ultrapassar muitas das fragilidades regionais por meio dos recursos próprios dos territórios (RIBEIRO; VAREIRO, 2007). Neste contexto, o empreendedorismo partilhado é fundamental (RODRIGUES, 2000 como citado por PELLIN, 2005), ou seja, um agir cooperativo, muitas das vezes em rede, associando agentes privados, o poder público e a própria comunidade local. Conclui-se que a área rural é uma espécie de "marca corporativa" e, por esse fato, é fulcral que certas condições sejam cumpridas em matéria da cooperação entre todos. Se essa cooperação não for bem conduzida, também o desenvolvimento será ineficaz.

Mas nem todas as regiões oferecem as mesmas condições para o desenvolvimento doturismo, considerando as imensas fragilidades dosterritórios rurais e do interior e, portanto, uma região com potencial de desenvolvimento deve, de fato, possuir algumas caraterísticas no domínio cultural, fisíco-natural e social que definam a sua identidade regional (CUNHA; CUNHA, 2005). Por exemplo, nem todas as áreas rurais são atrativas para os turistas rurais por serem muito remotas, ou por não terem fontes de atração cênica e/ou de patrimônio (OECD, 1994) e o fato de disponibilizarem condições ao nível de alojamento também não garantem a captação da procura. O pacote tem de ser suficiente para atrair e manter os turistas, oferecendo condições para a despesa (GANNON, 1994). Também é fulcral considerar que o desenvolvimento e a organização do turismo rural impõem um investimento significativo, que nem sempre está disponível (FLEISHER; FELENSTEIN, 2000). Para além disso, por vezes as próprias comunidades locais e os empresários podem considerar difícil a adaptação ao novo papel de "servilismo" (FLEISCHER; PIOZAM, 1997). Para além dos aspetos 
referidos, os territórios que promovem o turismo rural deverão ter produtos e serviços de qualidade que vão ao encontro das exigências e das expetativas dos turistas. Por fim, as empresas de turismo rurais muitas vezes continuam a não ter competências nem recursos para um efetivo marketing (SHARPLEY, 2005). Fica claro que o desenvolvimento do turismo não constitui sempre a "tábua de salvação" de territórios rurais que, por si, já têm uma economia rural muito fragilizada (BUTLER; CLARK, 1992 como citado por HALL; PAGE, 2006).

Pelas considerações feitas a propósito da importância do turismo nas regiões rurais, pode-se dizer que a atividade turística pode ter uma função dominante ou uma função estruturante, como pode e apenas ter uma função complementar ou até meramente residual, a depender de onde se localizam as atividades e da importância que assumem nas economias dessas mesmas regiões (SILVA, 2006). Significa, então, que nos próprios territórios o turismo pode-se encontrar em situações distintas. Podem-se considerar os espaços em que o turismo não é central, passando por outros onde este constitui uma aposta de reconversão e modernização do sistema produtivo, e até regiões ou locais onde o turismo constitui um pilar estrutural do desenvolvimento econômico e social (SILVA; PERNA, 2002).

\section{COOPERAÇÃO, STAKEHOLDERS E DESENVOLVIMENTO TURÍSTICO}

É uma realidade que, devido à natureza fragmentada do turismo, as organizações e as empresas que operam no setor turístico procuram cada vez mais modelos de cooperação de modo a ultrapassarem, eficazmente, os constrangimentos próprios de um ambiente crescentemente caraterizado pela competitividade e por mudanças nos paradigmas ao nível da procura turística (COSTA; SANTOS; FERREIRA, 2007). Neste contexto há que considerar a atividade de uma forma sistêmica, que se justifica pelo turismo ser um setor que tem uma série de interdependências entre atores, sejam estes organizações, turistas, instituições ou empresários, que cooperam e competem no mesmo espaço (MIGUÉNS, 2009). Aliás, a implementação de qualquer estratégia de desenvolvimento "exige" a participação de uma série de partes relacionadas com o turismo. Primeiramente, dever-se-á considerar os que desenvolvem, ou 
seja, os empresários ou as organizações que iniciam um projeto e que conciliam uma série de recursos e competências para concretizá-lo, em nível financeiro e profissional. Estes atores podem ser individuais (como proprietário de um terreno) ou coletivos, como uma empresa comercial ou uma organização pública (BAUD-BOVY; LAWSON, 2002). Em segundo, dever-se-á considerar os intermediários que constituem as agências e os operadores que estabelecem as ligações entre os serviços e a potencial clientela. Podem aqui ser incluídos, nomeadamente, as agências de viagens, os operadores turísticos, os transportes, as agências de informação e de promoção. Um terceiro grupo será composto pelas autoridades nacionais, regionais e locais que, no fundo, são as organizações que desempenham um papel essencial em termos de planejamento, tomada de decisão, legislação, investimento nas infraestruturas, e que desenvolvem as estruturas organizacionais, possibilitando a colaboração entre as entidades públicas e o setor privado (BAUD-BOVY; LAWSON, 2002).

Diversos são os estudos desenvolvidos sobre a necessidade das organizações turísticas criarem ligações com os atores, no fundo, relações de caráter interorganizacional. Os estudos tradicionais sobre as relações interorganizacionais (e.g. JAMAL; GETZ, 1995), a investigação sobre as parcerias no turismo (SELIN; BEASON 1991; JAMAL; GETZ 1995; LONG, 1997 como citado por CAFFYN, 2000), a teoria da participação da comunidade (community based participation) desenvolvida por Murphy (1985) e Hall (1999), assim como os paradigmas do desenvolvimento e turismo sustentável e ainda as abordagens do planejamento colaborativo, integrado e interativo (INSKEEP, 1991; TIMOTHY, 1999, GETZ, 1987 como citado por TIMOTHY, 1999; GUNN, 1988 e 1994), destacam a importância do estabelecimento de relações de cooperação e colaboração entre os agentes turísticos. Pressupõem ainda o envolvimento da comunidade na gestão do destino devido ao seu papel como ator chave. Nesta última situação, isso normalmente poderá significar trabalhar com a indústria e os grupos representantes da comunidade no contexto do destino, em vez de operar por meio de mecanismos mais extensos e alargados de participação pública. Aliás, na perspectiva do desenvolvimento e do turismo sustentável, é comum a literatura referir-se à necessidade de parcerias e de colaboração como elementos chave, em particular quando uma grande variedade de atores da comunidade local tem a capacidade de desempenhar um papel ativo no 
processo (CAFFYN, 2000). Defendendo-se, repetidamente, uma abordagem holística e multidisciplinar do turismo sustentável (BRAMWELL; HENRY; JACKSON; van der STRAATEN, 1996), há um quase que universal consenso que a participação comunitária no processo de desenvolvimento é um elemento essencial (CAFFYN; JOBBINS, 2003).

Numa perspectiva claramente inter-relacional, a literatura considera essencial a união de esforços entre os vários atores de vários subsetores sob fórmulas de cooperação, colaboração, parcerias e/ou redes, constituindo um processo interativo, com partilha de regras, normas e estruturas, a um determinado nível organizacional, numa delimitada área geográfica, procurando decidir sobre aspetos e questões relacionadas com o desenvolvimento turístico (LONG, 1997 como citado por CAFFYN, 2000; LONG, 2000). Constata-se, pois, que tanto os acadêmicos como os vários intervenientes do setor turístico reconhecem, nas diferentes formas de parcerias, a capacidade de poderem resolver alguns dos problemas com que as organizações e os destinos lidam atualmente, apesar da constituição de parcerias duradouras e produtivas não ser realmente uma tarefa de fácil execução (COSTA; SANTOS; FERREIRA, 2007).

O trabalho de Palmer e Bejou (1995) veio despertar o interesse em aprofundara temática da cooperação entre atores sociais para o desenvolvimento do turismo. Os autores argumentaram a favor da cooperação entre os stakeholders, porque consideram que os mesmos, isoladamente, têm menos impacto promocional nos potenciais turistas e aqueles atores podem atingir mais eficientemente os seus objetivos, reconhecendo as suas interdependências. Quando os objetivos podem ser alinhados, as organizações podem decidir cooperar nas trocas e nessa cooperação pode incluir-se qualquer atividade voluntária entre duas organizações que têm consequências para a realização dos seus respetivos objetivos (SHEEHAN; RITCHIE, 2005).

A evolução do paradigma do planejamento do turismo tem, também, justificado cada vez maior relevância atribuída à necessária cooperação entre os atores sociais para o desenvolvimento do turismo. Em grande parte dos países ocidentais, o planejamento tradicional entrou em descrédito, por apenas estar preocupado com a dimensão física e promocional e aposta-se, cada vez mais, num 
planejamento mais equilibrado em que se reconhece, claramente, a necessidade de um maior envolvimento da comunidade em geral e uma maior sensibilidade ambiental (TIMOTHY, 1999). As abordagens mais atuais do planejamento requerem a participação e a interação entre os vários níveis de uma organização, ou unidade de governação e entre uma organização responsável e os stakeholders, para concretizar parcerias horizontais e verticais dentro do processo planejamento (HALL; McARTHUR, 1998 como citado por HALL, 1999). Estas perspectivas do planejamento no turismo colocam, pois, a grande ênfase no papel de um grande conjunto de atores como a melhor forma de se atingir o interesse público, em vez de se planear para um pequeno grupo de empresários, ou de interesses privados, numa dimensão corporativa (HEALEY, 1997; HALL, 1999).

Os vários estudos, entretanto, realizados (particularmente desde os anos 80 do século $X X)$ demonstram a necessidade de descentralizar o planejamento e de integrá-lo nos objetivos do desenvolvimento da comunidade (PEARCE, 1989). A participação pública, aos vários níveis no desenvolvimento do turismo, tem sido muito valorizada pelos mais importantes especialistas na área (e.g. GUNN, 1994; INSKEEP, 1991; MURPHY, 1989) e, segundo os mesmos, pode ser vista na perspectiva do processo de tomada de decisão ou dos benefícios do desenvolvimento turístico. Esta participação pública pode envolver, primeiramente, os residentes locais, dando-lhes mais poder para determinar os seus próprios objetivos para o desenvolvimento e procurandose escutá-los para determinar quais são as suas percepções, relativamente aos impactos do turismo no seu território. Mas esta não foi a perspectiva pela qual a investigadora se interessou. A outra perspectiva identificada pelos autores, relativamente à participação pública no processo de desenvolvimento turístico e sobre a qual assentou a presente investigação, está relacionada com o envolvimento de outros atores e grupos de interesse no processo de decisão. Também Jamal e Getz (1995) defendem essa perspectiva, sobretudo num contexto do planejamento colaborativo centrado na comunidade com a necessidade de constituir organizações para gerirem as relações subjacentes ao desenvolvimento turístico na comunidade e na região.

As abordagens ao planejamento do desenvolvimento do turismo advogam também a necessidade de os atores cooperarem sob a forma de parcerias 
que constituem uma dos tipos de cooperação mais identificados no turismo. Segundo Selin (1999), as parcerias têm surgido como uma estratégia para a implementação de um caminho sustentável para o desenvolvimento turístico. Uma razão chave para o crescente interesse no desenvolvimento de parcerias no turismo é a crença de que as áreas de destino turístico e as organizações têm capacidade de ganhar vantagem competitiva, trazendo para o conjunto conhecimento, experiência, capital e outros recursos de vários atores (KOTLER; HAIDER; REIN, 1993). Neste sentido, a maioria das parcerias descritas na literatura, associadas ao desenvolvimento sustentável, é denominada de iniciativa intersetorial já que envolve representantes da indústria, do governo e dos setores voluntários. De fato, a literatura sobre esta problemática tem focalizado muito mais a atenção nas formas de colaboração e cooperação entre os setores, em particular entre o setor público e o setor privado e a própria comunidade local (ex. INSKEEP, 1991; WOOD; GRAY, 1991; BROHMAN, 1996; RHODES, 1996; TIMOTHY, 1998; BRAMWELL; SHARMAN, 1999; CAFFYIN, 2000; PARKER, 2000; BRAMWELL; LANE, 2000; CAFFYIN; JOBBINS, 2003; WALIGO; CLARKE; HAWKINS, 2015). A defesa da tese que o planejamento turístico e o desenvolvimento sustentável do turismo deverão ser interativos, entre os vários atores do turismo, particularmente entre o setor público e setor privado, numa relação simbiótica (TIMOTHY, 1998), aplica-se aqui na perfeição e fundamenta o interesse desta investigação.

\section{TURISMO EM PORTUGAL E NO ALENTEJO}

Primeiramente, opta-se por apresentar, e de forma resumida, o papel do turismo como atividade econômica em Portugal e, posteriormente, abordarse-á o protagonismo daquela atividade numa região, geograficamente, de interior e com fortes caraterísticas rurais.

O turismo é uma das atividades econômicas com maior importância na economia nacional portuguesa, com um forte impacto no Produto Interno Bruto (PIB) nacional e no emprego, para além de ter um papel preponderante no investimento e no desenvolvimento de outras atividades. Como é de conhecimento generalizado, várias economias europeias (e não europeias) 
entraram em crise nos últimos anos. O caso de Portugal não foi diferente e entrou numa forte crise, a partir de 2011, com consequências significativas ao nível econômico, financeiro e social. Porém, e a partir de 2014, a atividade econômica começou a revelar sinais de recuperação, e o próprio "(...) Produto Interno Bruto (PIB) aumentou 0,9\% em volume, após uma variação negativa de 1,6\%" (INE, 2015, p.25) face ao ano anterior.

A posição do país face ao Turismo tem melhorado e muito nos últimos anos. No presente ano, Portugal ocupa o 15. a no ranking mundial dos destinos mais competitivos. Muitas das cidades principais portuguesas são reconhecidas como muitos atrativas pela sua história e patrimônio (ex. Lisboa, Porto ou Coimbra). Algumas praias são, igualmente, reconhecidas como as melhores do mundo (ex. praias no Algarve).

Em termos de atividade de alojamento turístico, e no ano de 2014, registouse uma evolução positiva, tendo a oferta turística aumentado $7 \%$ no número de estabelecimentos, e 5\% na capacidade de camas. As diárias atingiram 48,8 milhões (um aumento de 12,1\% face ao ano anterior), tendo os hóspedes atingido os 17,3 milhões, representando um aumento de 13,9\%. (INE, 2015). As receitas totais dos estabelecimentos atingiram os 2,3 mil milhões de euros $(+12,9 \%)$, enquanto as receitas de aposento totalizaram 1,6 mil milhões (+14,1\%) (INE, 2015). A grande maioria dos turistas que visita Portugal é proveniente do próprio país (turismo interno) e do restante de países da Europa (Espanha, Reino Unido, França e Alemanha), países emissores que representaram $57,3 \%$ do total de receitas em 2014. (INE, 2015). O turismo interno contribui muito para as diárias. Em 2014, cerca de 4,14 milhões de residentes em Portugal. 39,8\% da população residente efetuou pelo menos uma viagem turística, o que representa um aumento de 3,9\%, face ao ano anterior (INE, 2015). "O número de dormidas decorrentes das viagens turísticas dos residentes em 2014 totalizou 74,8 milhões, $+1,8 \%$ relativamente ao ano anterior. Essas dormidas distribuíram-se por 62,1 milhões em Portugal ( $+3,0 \%)$ e 12,7 milhões no estrangeiro (-3,6\%)." (INE, 2015, p.34). 
Figura 1. Mapa de Portugal por regiões

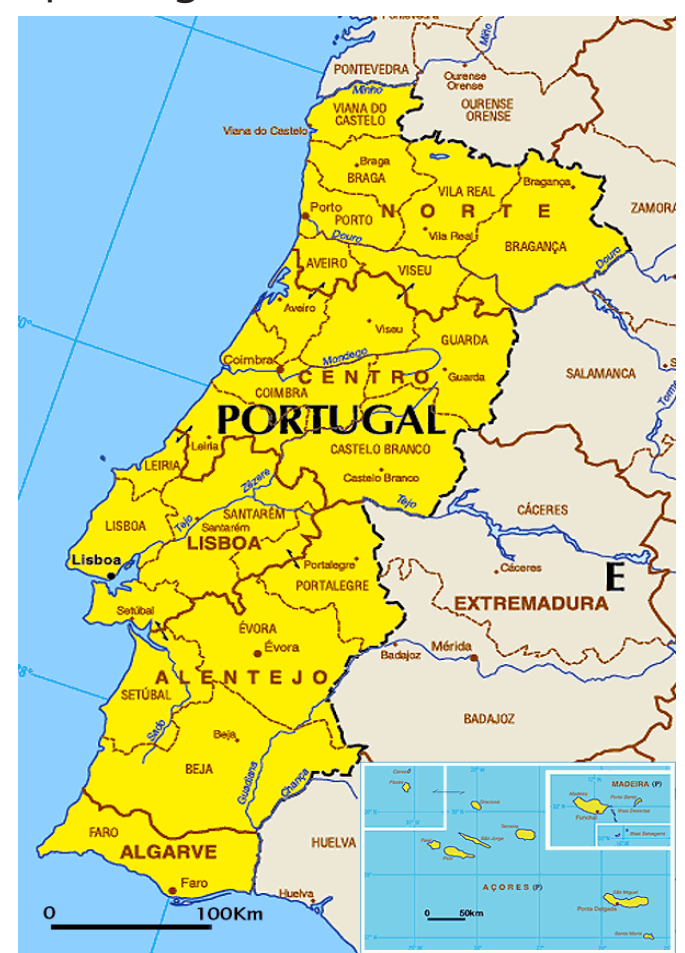

Fonte: embpomex.wordpress.com.

Considerando as regiões do país, resulta que "(...) a região que concentrou um maior número de dormidas foi o Algarve, que somou 15,9 milhões de dormidas, $25,6 \%$ do total (23,8\% em 2013). A região Centro apresentou valores muito aproximados: 15,8 milhões de dormidas e 25,5\% do total (25,4\% em 2013). As Regiões Autónomas permaneceram distanciadas das regiões do Continente, com 1,9\% nos Açores e 1,6\% na Madeira, pesos ainda assim superiores aos registados em 2013: 1,7\% e 1,2\%, respectivamente". (INE, 2015, p.50)

Tendo em consideração a globalidade dos estabelecimentos de alojamento turístico, "(...) em 2014 estavam em atividade 3578 estabelecimentos, abrangendo hotelaria, turismo no espaço rural e de habitação e ainda alojamento local. A capacidade disponível era de 151,9 mil quartos e 342,5 mil camas. (...) A hotelaria abrangeu 83,2\% das camas disponíveis, as quais estavam distribuídas por 1550 estabelecimentos (43,3\% do total). No alojamento local o número de unidades correspondeu a 32,0\% do total de estabelecimentos e 12,8\% da capacidade (camas) de alojamento. As unidades de turismo no espaço rural e de habitação (24,7\% do total) disponibilizaram 4,0\% das camas oferecidas" (INE, 2015, p.51). Apresentam-se agora alguns dados para posicionar a região Alentejo e subregião Baixo Alentejo, comparativamente com as restantes regiões: 
Quadro 1 - Estabelecimentos segundo o tipo, por região NUT

\begin{tabular}{|c|c|c|c|c|c|c|c|c|}
\hline NUT & $\begin{array}{c}\text { Total } \\
\text { geral }\end{array}$ & $\begin{array}{c}\text { Total } \\
\text { hotelaria }\end{array}$ & Hotéis & $\begin{array}{c}\text { Apart. } \\
\text { turísticos }\end{array}$ & $\begin{array}{c}\text { Aldeamentos } \\
\text { turísticos }\end{array}$ & $\begin{array}{c}\text { Hotéis } \\
\text { aparta- } \\
\text { mentos }\end{array}$ & Pousadas & $\begin{array}{c}\text { TER } \\
\mathbf{e} \\
\text { TH }^{2}\end{array}$ \\
\hline PORTUGAL & 3578 & 1550 & 1121 & 195 & 46 & 145 & 35 & 883 \\
\hline Continente & 3059 & 1344 & 983 & 175 & 45 & 109 & 32 & 760 \\
\hline Norte & 922 & 304 & 275 & 13 & 2 & 6 & 8 & 331 \\
\hline Centro & 685 & 299 & 272 & 8 & 3 & 8 & 8 & 165 \\
\hline Lisboa & 480 & 252 & 225 & 5 & 4 & 14 & 4 & 29 \\
\hline Alentejo & 412 & 112 & 85 & 8 & 2 & 8 & 9 & 195 \\
\hline Algarve & 560 & 377 & 126 & 141 & 34 & 73 & 3 & 40 \\
\hline $\begin{array}{c}\text { Região } \\
\text { autónoma } \\
\text { dos Açores }\end{array}$ & 163 & 82 & 66 & 11 & 0 & 3 & 2 & 81 \\
\hline $\begin{array}{c}\text { Região } \\
\text { autônoma } \\
\text { da Madeira }\end{array}$ & 356 & 124 & 72 & 9 & 1 & 33 & 1 & 42 \\
\hline
\end{tabular}

Fonte: INE, 2015, p.78

Refira-se que "(...) as regiões com maior capacidade de alojamento, quer a nível do número de estabelecimentos quer das camas disponíveis foram o Norte (37,5\% do total de estabelecimentos e 36,5\% das camas), o Alentejo (22,1\% e $25,7 \%)$ e o Centro (18,7\% e 18,4\%)" e a "(...) evolução das dormidas por regiões foi globalmente positiva, salientando-se o Alentejo (+26,0\%) e o Centro (+20,2\%)." (INE 2015, p.51). Observa-se que o Alentejo tem, em termos de oferta de TER e $\mathrm{TH}$, uma expressão mais significativa, posicionando-se no $2^{\circ}$ lugar.

Quadro 2 - Diárias de viagens com destino Portugal, por NUTS II

\begin{tabular}{|c|c|}
\hline NUTS de destino & Total geral \\
\hline Total & 62067,9 \\
\hline Norte & 13604,5 \\
\hline Centro & 15798,7 \\
\hline Lisboa & 8911,9 \\
\hline Alentejo & 5639,0 \\
\hline Algarve & 15915,5 \\
\hline Região Autonoma Açores & 1205,4 \\
\hline Regiäo Autónoma Madeira & 992,9 \\
\hline
\end{tabular}

Fonte: INE 2015, p.78, adaptado.

A evolução verificada nas regiões relativamente às diárias "(...) foi globalmente positiva, destacando-se Lisboa (+18,2\% de dormidas que em 2013) e Alentejo (+17,5\%). As principais regiões de destino foram o Algarve (34,0\%), Lisboa (25,2\%), Madeira (13,3\%) e Norte (12,4\%)." (INE, 2015, p.51). 
O Baixo Alentejo representa uma das quatro sub-regiões do Alentejo. As restantes denominam-se por Alto Alentejo (Portalegre), Alentejo Central (Évora) e Alentejo Litoral (Sines). O Baixo Alentejo integra a extensa Região Alentejo, sendo limitado a norte pelo Distrito de Évora, a leste pela Espanha, e a sul pelo Distrito de Faro. Esta sub-região integra 13 municípios: Aljustrel, Almodôvar, Alvito, Barrancos, Beja, Castro Verde, Cuba, Ferreira do Alentejo, Mértola, Moura, Ourique, Serpa e Vidigueira e 83 freguesias. O Baixo Alentejo é uma sub-região da extensa Região do Alentejo, abrangendo uma área de $8.544,6 \mathrm{~km}^{2}$, correspondente a $10,8 \%$ do território nacional. A área média das freguesias desta sub-região é de $102,9 \mathrm{~km}^{2}$, bastante superior à média nacional $\left(21,7 \mathrm{~km}^{2}\right)$. A densidade populacional do Baixo Alentejo corresponde a 14,77 $\mathrm{hab} / \mathrm{km}^{2}$. A população residente na área é de 126.192 indivíduos. Apresenta-se, em seguida, a comparação com o restante do território.

Quadro 3 - Dados sobre o território Baixo Alentejo (Censo 2011)

\begin{tabular}{|c|c|c|c|c|}
\hline & Área $\mathbf{( k m}^{2}$ ) & $\begin{array}{c}\text { Percentagem } \\
\text { do território } \\
\text { português }\end{array}$ & $\begin{array}{c}\text { População } \\
\text { Residente }\end{array}$ & $\begin{array}{c}\text { Densidade } \\
\text { Populacional }\end{array}$ \\
\hline Portugal & $92.089,7 \mathrm{~km}^{2}$ & --- & 10.561 .614 & $114,7 \mathrm{hab} / \mathrm{km}^{2}$ \\
\hline Alentejo & $31.551,8 \mathrm{~km}^{2}$ & $34,26 \%$ & 757.190 & $24 \mathrm{hab} / \mathrm{km}^{2}$ \\
\hline Baixo Alentejo & $8.544,6 \mathrm{~km}^{2}$ & $10,8 \%$ & 126.192 & $14,77 \mathrm{hab} / \mathrm{km}^{2}$ \\
\hline
\end{tabular}

Fonte: www.ine.pt.

Em termos comparativos, a NUT Norte é a região mais povoada (3.689.609), seguida da NUT Lisboa (2.821.699) e em terceiro lugar a NUT Centro (2.327.580). O Alentejo surge na $4^{a}$ posição, vindo depois as restantes regiões (Algarve, Madeira e Açores, respetivamente). Considerando os aspetos topográficos pode-se dizer que o Alentejo é, carateristicamente, uma zona de planície, sem uma bacia hidrográfica muito significativa. Mas é precisamente no Baixo Alentejo que se localizam, ou circulam, dois rios importantes, com as suas afluentes em ribeiras conhecidas e até exploradas em termos de turismo. É o caso do rio Sado, que 
tem a sua afluente na Ribeira do Roxo, com uma importante Barragem do Roxo localizada em Beja (freguesia de Sta. Vitória); e o Rio Guadiana, que circunda importantes municípios do Baixo Alentejo (mas não só), como Moura, Serpa, Mértola e Almodôvar. No que diz respeito à natureza, pode-se dizer que o Alentejo tem importantes zonas que são protegidas, representando 191.922ha. O Baixo Alentejo apresenta a maior fatia desse território, sendo que 69.655ha é considerado área protegida. Esse fato é bastante significativo em termos das preocupações políticas na proteção da natureza, o que limita, positivamente, a eventual massificação turística. Perante isso, os planos de ordenamento de território limitam a construção, sobretudo em termos de turismo, sendo que no caso do Baixo Alentejo, apenas 126 ha de solo é utilizado para fins turísticos.

O Baixo Alentejo, tal como o Alentejo em geral, constitui uma zona muito abrangente, com uma forte dispersão geográfica, mas que padece dos tradicionais problemas das regiões rurais e do interior: desertificação, envelhecimento da população, dependência de atividades do setor primário, desemprego, êxodo, etc. A economia regional apresenta uma especialização relevante do setor agrícola, muito embora as atividades relacionadas com o setor dos serviços estejam ganhando cada vez mais relevância relativa. Como motor da economia alentejana, encontram-se alguns dos subsetores da atividade agroindustrial, que ganham protagonismo nos mercados nacionais e internacionais, mostrando-se muito competitivos.

Os dados atualizados sobre a atividade turística, relativamente às sub-regiões do Alentejo são insuficientes (só se obteve para 2012), mas considerando o Alentejo e as suas quatro sub-regiões, concluiu-se que o Alentejo Central surgia como a sub-região com maior número de diárias (389.280), ocupando o Baixo Alentejo a penúltima posição (142.039). Os turistas emissores para o Alentejo são, na grande maioria, portugueses, seguido dos espanhóis, os ingleses, os franceses e os alemães.

O Alentejo é, na realidade, a região que apresenta uma estada média mais baixa, na ordem dos 1.8, sendo mais elevada na sub-região do Alentejo Litoral (2.4) e mais baixa no Baixo Alentejo (1.6) e Alto Alentejo (1.4). Em termos do número de estabelecimentos hoteleiros, constata-se também que a maioria 
dos estabelecimentos se concentra no Alto Alentejo (47) e o Baixo Alentejo fica na última posição entre as quatro sub-regiões (25).

\section{METODOLOGIA}

As opções tomadas no nível metodológico permitiram uma melhor compreensão da percepção da importância atribuída pelos atores sociais do turismo, na posição de dirigentes dos setores público, privado e associativo, relativamente à necessidade de haver cooperação, intersetorial e interorganizacional, para o desenvolvimento turístico e a competitividade dos territórios rurais e, em especial, da sub-região do Baixo Alentejo. Essas opções implicaram delinear um desenho de investigação que envolvesse uma população de agentes dispostos a participarem com a sua opinião e percepção relativamente ao problema em investigação, contribuindo assim para uma melhor compreensão do fenômeno. A participação e o envolvimento dos mesmos no processo de investigação foram concretizados por meio do recurso a instrumentos apropriados de recolhimento de dados de caráter essencialmente quantitativo.

O estudo empírico, realizado no âmbito da tese de Doutorado em Turismo, procurou dar resposta a um conjunto de objetivos, sendo que parte deles reportou-se neste artigo. O estudo em questão baseou-se na elaboração de um questionário que, com um conjunto de questões fechadas, foi aplicado a dirigentes de organizações do setor público e associativo, e a empresários do turismo (alojamento, restauração, animação turística, aluguel de veículos) da subregião do Baixo Alentejo. Os questionários foram aplicados durante os meses de julho e novembro de 2011 à totalidade dos dirigentes dos setores públicos ao nível das autarquias (presidentes de câmara ou vereadores do turismo dos 13 municípios), órgãos regionais de turismo, aeroporto, caminho de ferro e instituições de ensino superior e profissional (total de 28 ) e setores associativo e misto, ou seja, associações de desenvolvimento, de empresários, comerciais e de municípios; comunicação social e sindicatos (total de 23) e a uma amostra de empresários dos vários subsetores, selecionada em função do critério do conselho mais procurado, medianamente e menos procurado identificados pelo número de visitantes registados nos postos de turismo dos 13 municípios da sub-região 
à data de 2010 (total de 134 empresas). Após a devolução dos questionários, obteve-se uma taxa de retorno de 52,4\% (97 respostas).

Com o apoio do software informático SPSS (versão 18), e tomando-se por base a percepção dos agentes questionados, relativamente à importância da cooperação e os seus impactos no desenvolvimento do turismo, optou-se por uma estratégia que teve por base compreender a perceção dos atores do turismo relativamente à importância da cooperação nas dimensões relacionadas com o fenômeno da cooperação (conceito de cooperação), as caraterísticas da cooperação, a importância das relações de cooperação entre setores, as vantagens da cooperação, as dificuldades da cooperação, entidades importantes com quem cooperar eáreas de cooperação. Perante as variáveis referidas, optou-se pela análise descritiva, designadamente proporções e medidas de tendência central e o teste não paramétrico de Friedman (MAROCO, 2007). Complementarmente, e para melhor compreender estas questões, recorreu-se ao teste do Qui-Quadrado, de modo a verificar o grau de dependência entre as várias dimensões do fenômeno da cooperação dentro de cada setor organizacional (público, associativo, privado, outro/misto). Recorreu-se, ainda, ao teste não paramétrico de Kruskal-Wallis, para conhecer a existência de diferenciação entre as percepções relativamente à importância da cooperação, assumindo também por setor organizacional. Para analisar a perceção dos atores inquiridos relativamente à importância da cooperação e os seus impactos no desenvolvimento turístico da sub-região, considerou-se adequado o procedimento estatístico da análise da regressão pósfatorial, isto é, antecedida por análises fatoriais com o objetivo de identificar as dimensões integradas das variáveis do questionário: caraterísticas da cooperação, fatores para o sucesso da cooperação, importância atribuída à cooperação com as entidades, vantagens e dificuldades da cooperação e áreas de cooperação.

\section{SÍNTESE DE RESULTADOS}

O estudo mostrou que os atores do turismo do Baixo Alentejo têm uma noção clara da importância do fenômeno cooperativo e das suas vantagens, destacando, primordialmente, e de acordo com os resultados do teste não paramétrico de Friedman $\left(\mathrm{N}=88 ; \chi^{2}=376,302 ; p=, 000\right)$ e de forma hierarquizada, a possibilidade 
do mesmo proporcionar meios mais eficazes e eficientes $(9,70)$, uma maior capacidade de competição das organizações no mercado $(9,23)$, uma partilha mais eficaz dos recursos e o reforço da legitimidade das políticas $(9,14)$.

O sucesso da cooperação por meio das parcerias tem subjacente um conjunto de fatores cuja importância se quis compreender em função da perceção dos atores do setor turístico do Baixo Alentejo. Os fatores versam dimensões como: confiança, trabalho de equipe, compromisso, liderança, envolvimento, mobilização de pessoal, comunicação, cultura e motivação. Procurou-se determinar a existência de diferenças significativas nos rankings das médias da opinião dos atores relativamente às dimensões dos fatores de sucesso da cooperação. Dos resultados obtidos através do teste de Friedman $\left(N=91 ; \chi^{2}=64,462 ; p=, 000\right)$, apurou-se que o fator que mais determina o sucesso da cooperação é o trabalho de equipe $(6,49)$, seguido da construção de confiança $(6,38)$ e da necessidade de um alto nível de compromisso $(5,97)$. Para que essa cooperação seja bem-sucedida, os agentes têm consciência que é essencial um trabalho em equipe, com uma boa dose de confiança e de compromisso. $O$ trabalho em equipe é um excelente meio para minimizar a tendência para uma competição individualizada, que retira a capacidade de poder das organizações. Porém alguns obstáculos podem impedir ou dificultar as relações de cooperação. De acordo com os resultados obtidos através do teste de Friedman $\left(N=81 ; \chi^{2}=87,856 ; p=, 000\right)$, conclui-se que a opinião da generalidade dos atores assentam no excesso de burocracia que torna morosa a execução das tarefas $(13,66)$; na falta de uma estratégia comum entre os parceiros (12,93); e nas condições financeiras $(12,88)$, usualmente deficitárias. Acresce que a hierarquização das dificuldades de cooperação realizada através do teste de Friedman [setor público $\left(\chi^{2}=62,250 ; p=, 000\right)$ e setor privado $\left.\left(\left(\chi^{2}=37,133 ; p=, 011\right)\right)\right]$ diferencia-se nos setores organizacionais (público, privado, associativo e outro/misto), destacando-se como fatores obstaculizantes ao processo de cooperação a falta de comunicação (atores do setor público), a falta ou as diferenças de competência organizacional e de gestão entre os atores-chave e a existência de uma cultura individualista (atores do setor associativo) e o favorecimento de "alguns" em desfavor de "outros" (atores do setor privado). 
Pelo estudo é permitido concluir-se que, em termos gerais, os dirigentes dos vários setores organizacionais (público, privado, associativo e outros/misto) do setor turístico valorizaram a importância de desenvolverem práticas de cooperação para estimular a atratividade e a competitividade da sub-região e identificaram áreas privilegiadas em que os vários atores podem cooperar. A partir dos resultados obtidos é fácil perceber que os atores questionados valorizam as medidas impulsionadoras da competitividade da sub-região que estejam relacionadas com o desenvolvimento do produto turístico e das atrações em si mesmas. Mais uma vez através do teste de Friedman $\left(N=90 ; \chi^{2}=72,470 ; p\right.$ $=, 000$ ) concluiu-se que a medida considerada mais importante relaciona-se com a necessidade de aumentar a oferta de pacotes, circuitos e de visitas organizadas $(\mathbf{7}, \mathbf{8 1})$, seguida da necessidade de aumentar a oferta de atrações e produtos temáticos $(\mathbf{7}, \mathbf{4 8})$ com pouca diferença, em termos médios, da necessidade de aumentar a promoção turística dos mesmos produtos temáticos $(\mathbf{7 , 4 6 )}$.

O desenvolvimento de um destino turístico depende de uma aposta clara nos produtos turísticos e isso dependerá da existência de uma coordenação entre várias entidades (LAZZERETTI \& PETRILLO, 2006). Para isso, o próprio produto turístico é definido como um conjunto de serviços que só existem por causa de uma atração, e daí não ser surpresa que haja uma valorização das duas medidas de atratividade por ambos os grupos de dirigentes. Verificouse, ainda, que os dirigentes, em particular do setor público, consideram ser importante uma aposta na melhoria da qualidade dos equipamentos e dos serviços turísticos $(6,96)$, algo que acaba por ser coerente com a necessidade de apostar nas atrações e no desenvolvimento do produto turístico na sub-região, se se considerar que a própria definição de produto turístico inclui, precisamente, as atrações turísticas e os serviços turísticos (ou facilidades) (IGNARRA, 2003). Os atores, sobretudo do setor público e setor privado, não deixaram também de considerar como prioritário o desenvolvimento de turismo organizado para o Baixo Alentejo, com a necessidade de aumentar a oferta de pacotes, circuitos e visitas organizadas para a sub-região [setor público $(8,36)$ e setor privado $(7,61)]$. A valorização daquelas medidas parece indicar uma percepção negativa sobre a organização da atividade turística na sub-região e aponta ainda para a percepção da existência de deficiências do lado da oferta turística da sub- 
região, as quais necessitam ser alvo de aposta estratégica no desenvolvimento da área, de forma a torná-la mais atrativa e competitiva.

Os resultados permitiram, ainda, verificar a grande necessidade de apostar no aumento da promoção turística dos produtos turísticos. Esta também foi a medida considerada prioritária, em particular pelos empresários, em termos das condições de atratividade e competitividade da sub-região. Considerando que o Baixo Alentejo (e o próprio Alentejo) é ainda uma zona embrionária em termos de desenvolvimento turístico, é preciso definir uma estratégia adequada para a divulgação dos recursos da mesma.

O estudo permitiu identificar as principais áreas em que os atores do turismo da sub-região podem cooperar, o que será importante para o desenvolvimento turístico do Baixo Alentejo. Com a aplicação do teste não paramétrico de Friedman $\left(\mathrm{N}=92 ; \chi^{2}=77,059 ; p=, 000\right)$, pode-se concluir que os dirigentes privilegiam a necessidade de cooperar na valorização dos recursos culturais locais e regionais $(5,95)$ e no desenvolvimento dos recursos e dos produtos turísticos $(5,78)$ e na organização conjunta de atividades de promoção $(5,44)$. Esta conclusão tem sentido quando o Baixo Alentejo (e o Alentejo em geral) possui uma grande variedade de recursos de qualidade que podem oferecer um excelente fator de diferenciação relativamente a outras regiões do país (e fora do país). Fica também clara a necessidade de as entidades desenvolverem esforços conjuntos para o desenvolvimento de produtos turísticos mais fortes para a sub-região/ região e a necessidade de promovê-los conjuntamente. Da análise dos dados ficou também patente a relevância atribuída pelos empresários ([setor privado - $\left(\chi^{2}=30,852 ; p=, 000\right)$ ] à importância de cooperar para o desenvolvimento da indústria de eventos e convenções $(5,29)$. O turismo de eventos e de convenções pode constituir uma importante área de investimento por ajudar a "combater" a sazonalidade, garantindo taxas de ocupação de alojamento mais distribuídas ao longo do ano (ANSARAH, 2000), gerando mais riqueza, mais investimento e mais dinâmica no território. $O$ turismo de eventos pode ser uma grande oportunidade para o desenvolvimento do turismo na sub-região e parece que os empresários têm essa consciência. Esse evento, ao ser captado, pode trazer, de uma só vez para o país/região, muitas pessoas que ajudarão também na promoção nacional e no exterior (VILLELLA, 2000 como citado por BATISTA, 2008). Esta será, provavelmente, 
a expetativa dos empresários quando destacam a necessidade de apostar neste segmento, já que o mesmo pode ser um excelente captador de fluxos de turistas, de mais receitas e, consequentemente, constituir um potencializador do desenvolvimento socioeconômico da sub-região e da própria região (BATISTA, 2008). No entanto, os dirigentes públicos regionais e locais desvalorizam aquela área em que se pode cooperar, colocando-a na última posição, o que vai, totalmente, contra a ideia de Britto e Fontes (2002 como citado por BATISTA, 2008), que afirmam que, em virtude do crescente desenvolvimento do turismo de eventos em nível mundial, despertou-se a consciência dos governos para a necessidade de investimentos na construção e/ou modernização de aeroportos, de centros de convenções e de hotéis de categoria superior. Não é, de fato, o caso da sub-região do Baixo Alentejo que, apesar de até ter um aeroporto, esta infraestrutura ainda está bastante subaproveitada.

A análise das preocupações das diferentes entidades relacionadas com a atividade turística e que deverão ser incluídas nas políticas de desenvolvimento turístico foi outro dos objetivos do estudo. O turismo é perspectivado pelos agentes como uma atividade econômica que tem evoluído muito nos últimos tempos e que terá muito potencial para o desenvolvimento da sub-região no futuro. Por meio do teste de Friedman, hierarquizaram-se as opiniões e verificouse uma identificação das mesmas atividades econômicas consideradas com maior potencial na região entre os atores respondentes dos quatro setores organizacionais, destacando-se o turismo $(\mathbf{5 , 7 6 )}$, a agricultura/produção animal $(\mathbf{5}, \mathbf{4 1})$ e a indústria transformadora agroalimentar $(4,38)$, apesar de haver uma atribuição de importância diferente dessas mesmas.

As atividades econômicas mais valorizadas podem ser relacionadas e numa visão sistêmica com o investimento no desenvolvimento de uma atividade pode impulsionar o desenvolvimento de outra. Os atores questionados referem-se ao potencial da agricultura e da produção animal no desenvolvimento do Baixo Alentejo. De fato, a agricultura continua a ser uma atividade econômica com grande peso na economia regional. A sub-região apresenta uma especialização relevante do setor agrícola, desenvolvendo as suas atividades em torno da silvicultura, da exploração das espécies cinegéticas, da agropecuária, pastorícia e produtos derivados, podendo tomar-se como exemplo a cortiça, o azeite 
(e.g. zona demarcada de Moura), os queijos (e.g. queijo de Serpa), os enchidos e presuntos (e.g.. porco preto de Barrancos), os vinhos (e.g. Vidigueira), a aguardente de medronho e o mel. Potanto estes recursos agrícolas podem ter um grande potencial para a oferta turística em termos de gastronomia, produtos temáticos e para o turismo de eventos, contribuindo assim para o desenvolvimento turístico da sub-região.

As atividades do turismo em si próprias têm vindo a revelar também um potencial de crescimento econômico para a sub-região. Essas atividades podem estar associadas à atividade turística nas vertentes do Turismo em Espaço Rural e na modalidade de Agroturismo. Por seu turno, o desenvolvimento daquelas modalidades de turismo pode ser um importante instrumento para a valorização dos produtos agrícolas de base local e para a

inovação em termos de animação ligada às atividades agrícolas. Existe também um potencial de desenvolvimento de algumas atividades turísticas relacionadas com a produção agrícola nas vertentes do vinho e do azeite, com uma influência clara em novas tipologias como o enoturismo, o turismo equestre, e com o desenvolvimento de rotas do azeite179 e na aposta em feiras com oferta de produtos agrícolas locais. Em relação a este último caso, existem já algumas feiras baseadas nos recursos endógenos da sub-região em termos agrícolas, produção alimentar e indústria agroalimentar, nomeadamente a OVIBEJA em Beja, a feira do queijo de Serpa, e a feira medieval das vilas de Mértola e de Almodôvar.

A indústria agroalimentar tem, também, uma grande relevância no Alentejo, e também em particular no Baixo Alentejo e, portanto, não surpreende que a mesma seja considerada de elevado potencial econômico para o desenvolvimento da subregião. Além disso, a relação dinâmica com as atividades econômicas anteriores pode justificar a necessidade de intervencionar mais na sua inovação. A indústria agroalimentar na região do Baixo Alentejo inclui indústrias de lacticínios, de produção de óleos e gorduras animais, de vegetais e fruta, e de abate de animais, de preparação e conservação de carne e produtos à base de carne (CCDR, 2004). Perante o potencial da atividade turística na sub-região, as percepções dos atores foram unânimes relativamente aos atributos turísticos que a sub-região tem e que podem mais facilmente atrair os turistas para o Baixo Alentejo. Atributos como a 
gastronomia, a singularidade do destino quanto aos seus recursos, a paisagem, a segurança, a tranquilidade, o patrimônio histórico-cultural e a disponibilidade e a qualidade dos serviços turísticos foram considerados como os mais relevantes da sub-região, o que está claramente em consonância com alguns dos estudos sobre esta problemática (CESTUR, 2007).

O estudo permite concluir que as áreas de intervenção em termos de políticas de desenvolvimento turístico para a sub-região pressupõem uma forte aposta no turismo organizado, na organização de packages e na definição de circuitos turísticos para a região, bem como uma melhoria da qualidade e dos serviços turísticos. Na definição de políticas de turismo, a promoção do destino com a grande preocupação na valorização dos produtos temáticos, associando aos atributos mais relevantes da própria sub-região (e.g. patrimônio natural e cultural e a gastronomia), são também aspetos importantes. As novas formas de turismo que associam as caraterísticas próprias da ruralidade e da atividade agrícola tradicional nomeadamente o agroturismo, o enoturismo e o turismo cinegético podem constituir, na percepção dos dirigentes e dos empresários, uma excelente oportunidade a considerar na política de desenvolvimento turístico da subregião do Baixo Alentejo (POA 2007-2013). É evidente, portanto, a percepção dos atores sobre a necessidade de haver articulação entre as potencialidades que a região/sub-região oferece para a dinamização de diversas formas de turismo (e.g. turismo em espaço rural, turismo cultural e turismo de natureza) e o tornar as "atrações regionais" mais competitivas, considerando os principais atributos do destino do Baixo Alentejo mais valorizados pelos agentes da sub-região.

\section{CONCLUSÃO}

Um dos aspetos centrais da presente investigação consistiu em demonstrar a grande importância da cooperação entre os atores sociais nos processos mais modernos de desenvolvimento e planejamento do território. Essa perspectiva é ainda mais real quando se trata do setor turístico, que por muitos é considerado como uma das ferramentas com elevado potencial para o crescimento econômico e o desenvolvimento regional, bem como uma arma poderosa para evitar a desertificação e a estagnação econômica das regiões, sobretudo as 
rurais (OPERMAN, 1993; TELFER; SHARPLEY, 2008 e 2002; JACKSON; MURPHY, 2006; FOTIADIS, 2009).

$\mathrm{Na}$ perspectiva dos atores a cooperação pode ser muito vantajosa para o turismo no Baixo Alentejo, em especial porque aumenta a competitividade empresarial, permite as trocas de recursos onde se inclui o capital, o conhecimento e reforça a legitimidade das políticas de turismo. Porém existem algumas dificuldades no processo de cooperação que na opinião da generalidade dos atores passam pelo excesso de burocracia que torna morosa a execução das tarefas, pela falta de estratégia comum e, ainda, pelas condições financeiras usualmente deficitárias.

Na promoção da cooperação entre setores ficou também evidente que os atores defendem a necessidade das relações interorganizacionais irem no sentido de apostar no aumento da promoção turística da sub-região, no aumento da oferta de atrações e produtos temáticos, no aumento da oferta de pacotes turísticos organizados, no aumento da oferta da qualidade de equipamentos e serviços turísticos, constituindo medidas relevantes para aumentar o poder de atratividade e de competitividade da sub-região. As principais áreas que os atores defendem em que devem cooperar baseam-se na valorização da cultura existente, no aproveitamento dos recursos turísticos e nas atividades promocionais e numa aposta clara no turismo de eventos e convenções. Mas estas conclusões estão em consonância com as grandes preocupações dos atores relativamente aos elementos a integrar nas políticas de desenvolvimento turístico para o Baixo Alentejo. De fato, fica evidente na análise de dados que é preciso considerar a necessidade de organizar o turismo em termos de circuitos e visitas, de haver um investimento claro na promoção, no desenvolvimento de produtos temáticos e no aumento da oferta de equipamentos e serviços turísticos.

\section{REFERÊNCIAS}

ANSARAH, M. (Coord.). Como aprender turismo - como ensinar - vol.2. 3. ed. S.Paulo: Senac, 2000.

BATISTA, A. Turismo de eventos: desafios prementes da cidade de João Pessoa. Tese de Mestrado em Gestão e Desenvolvimento de Turismo. Aveiro: Universidade de Aveiro, 2008. 
BAUD-BOVY, M.; LAWSON, F. Tourism and recreation. Handbook of Planning and Design, Oxford: Elsevier Science Lda, 2002.

BRAMWEII, B.; HENRY, I.; JACKSON, G.; van der STRAATEN. A framework for understanding sustainable tourism management. In BRAMWELL, B.; HENRY, I.; JACKSON, G.; PRAT, A.; G. RICHARDS, G.; STRAATEN, J. Sustainable Tourism Management: Principles and Practice. Netherlands: Tilburg University Press, 1996.

BRAMWELL, B.; LANE, B. Tourism collaboration and partnerships: politics, practice and sustainability. Clevedon: Channel View Publications, 2000.

BRAMWELL, B.; SHARMAN, A. Collaboration in local tourism policymaking. Annals of Tourism Research, vol.26, n. ${ }^{\circ 2}$, pp.392-415, 1999.

BROHMAN, J. New directions in tourism for third world development, Annals of Tourism Research. vol.23, n. ${ }^{\circ} 1$, pp.48-70., 1996.

CAFFYN, A. Is there a tourism partnership life cycle? In BRAMWELL, B.; LANE, B. (Eds). Tourism collaboration and partnerships - politics, practice and sustainability. Clevedon: Chanel View Publications, pp. 200-229, 2000.

CAFFYN, A.; JOBBINS, G. Governance capacity and stakeholder interactions in the development and management of coastal tourism: examples from Marocco and Tunisia. Journal of Sustainable Tourism. vol.11, n. ${ }^{\circ 2} / 3,224-245,2003$.

CAMPANHOLA, C.; SILVA, J. Tourism in the rural área as a new opportunity for small farmers. Texto para Discussão. N. ${ }^{\circ}$ 72, IE/UNICAMP, 1999.

CARVALHO, M.; LIMA, J.; KASTENHOLZ, E. Criatividade Cultural - que oportunidade para destinos rurais. PASOS Revista Turismo \& Património Cultural. vol. 12, n. ${ }^{03}$, pp.635-648, 2014.

CESTUR; Características do turismo interno em Portugal. Escola Superior de Turismo e Hotelaria do Estoril. 2007 http://www.observatorioturismoalentejo.pt/images/files/cestur _caracterizacao_turismo_interno_portugal. Acesso em: 12 jan. 2012

COSTA, C.; SANTOS, M.; FERREIRA, A. Relações interorganizacionais no turismo - parceria entre operadores turísticos alemães e os agentes da oferta algarvia. Revista Encontros Científicos, n. ${ }^{03}$, Universidade do Algarve, 2007.

CUNHA, S.; CUNHA, J. Competitividade e sustentabilidade de um cluster de turismo: uma proposta de modelo sistémico de medida do impacto do turismo no desenvolvimento local. Revista de Administração Contemporânea, vol.9, n. ⒉ pp.63-79, 2005. 
DINIS, A. Tourism, niche strategy and networks as factors for both entrepreneurship and rural sustainability. IX Rural Entrepreneurship Conference: a sustainable rural. pp.21-29, 2011.

ELIAS, N. O potencial e viabilidade das parcerias público-privadas no turismo em Portugal: a visão dos operadores do sector. Dissertação de Mestrado. Universidade de Lisboa: Instituto Superior de Economia e Gestão, 2014.

EURICO, S.; OLIVEIRA, F. Sustainable Tourism Development of Rural Destinations. In MORPETH \& YAN (Eds). Planning for tourism - towards a sustainable future, Oxford: Cabi Tourism Texts, 2015.

FLEISCHER, A.; FELSENSTEIN, D. Support for rural tourism: does it make a difference? Annals of Tourism Research, vol.27, n. ${ }^{\circ 4}$, pp.1007-1024, 2000.

FLEISCHER, A.; PIZAM, A. Rural tourism in Israel. Tourism Management, vol.18, n. ${ }^{\circ} 6, \mathrm{pp}$. 367-372, 1997.

FOTIADIS, A. The role of tourism in rural development through a comparative analysis of a Greek and a Hungarian rural tourism area. Tese de Doutoramento (PhD Thesis). University of Pécs, 2009.

GANNON, A. Rural tourism as a factor in rural community economic development for economies in transition. Journal of Sustainable Tourism, vol.2, n. ${ }^{\circ} 1 / 2$, pp.51-60, 1994.

GOELDNER, C.; RITCHIE, J. Tourism - principles, practices and philosophies. 11th ed. Oxford: Wiley and Sons, 2009.

GUNN, C. Tourism planning - basics, concepts, cases. 4th ed, Washington, D.C.: Taylor \& Francis, 1994.

GUNN, C. A. Tourism planning, New York: Taylor\&Francis, 1988.

HALL, M. Rethinking collaboration and partnership: a public policy perspective. Journal of Soustainable Tourism, vol. 6, n.³/4, pp.274-289, 1999.

HALL, M.; PAGE, S. The geography of tourism and recreation: environment, place and space. (3rd ed), New York: Routledge, 2006.

HEALEY, P. Collaborative planning - shaping places in fragmented societies, Vancouver: UBC Press, 1997.

IGNARRA, L. Fundamentos do turismo. 2. ed. São Paulo:Thompson, 2003. 
INSKEEP, E. Tourism Planning - an integrated and sustainable development approach, New York: Van Nostrand Reinhold, 1991.

INSTITUTO NACIONAL DE ESTATÍSTICA. Estatísticas de Turismo 2014, INE, 2015.

JACKSON, J.; MURPHY, P. Clusters in regional tourism - an Australian case. Annals of Tourism Research, vol.33, n. ${ }^{\circ 4}$, pp.1018-1035, 2006.

JAMAL, T.; GETZ, D. Collaboration theory and community tourism planning. Annals of Tourism Research, vol.22, n. ำ, pp.186-204, 1995.

KASTENHOLZ, E. Estudios de turismo rural $\mathbf{Y}$ cooperación entre Castilla $\mathbf{Y}$ León $\mathbf{Y}$ Portugal. Ediciones Salamanca: Universidad de Salamanca, 2010.

KASTENHOLZ. E. The role and marketing implications of destination images on tourist behaviour: the case of Northern Portugal. Tese de Doutoramento, Aveiro: Universidade de Aveiro, 2002.

KIMBU; NGOASONG. Centralised decentralisation of Tourism development: a network perspective. Annals Tourism Reseach. vol.40, pp.235-259, 2013.

KOTLER, P.; HAIDER, D.; REIN, I. Marketing places. Attracting investment, industry, and tourism to cities, states and nations. USA: Simon \& Schuster Inc, 1993.

LAZZERETTI, L.; PETRILLO, C. Tourism, local systems and networking. Oxford: Elsevier, 2006.

LONG, P. Tourism development regimes in the Inner City Frindge: the case of discover Islington, London. In: BRAMWELL, B. \& LANE, B. (Eds). Tourism collaboration and partnerships politics, practice and sustainability. Clevedon: Chanel View Publications, 2000.

MAROCO, J. Análise estatística com utilização do SPSS. Lisboa: Edições Sílabo, 2007.

MASON, P. Tourism impacts, Planning and Management. 3.rd edition. New York: Routledge, 2008.

McINTOSH, R., GOELDNER, C.; RITCHIE, J. Turismo - planeación, administración y perspectivas. (2. ${ }^{a}$ Ed.), Balderas: Editorial Limusa S.A, 2004.

MIGUÉNS, J. Networked tourism: from world destinations to inter-organizations. Tese de Doutoramento, Universidade de Aveiro, Aveiro, 2009.

MURPHY, P. Tourism: a community approach. Cambridge: University Press, 1985.

ORGANISATION FOR ECONOMIC CO-OPERATION AND DEVELOPMENT (OECD). Tourism strategies and rural development. Paris: OECD, 1994.

Revista Turismo - VisÃo e Ação - EletrônicA, Vol. 18 - N. 1 - JAN. - ABR. 2016 
OPPERMAN, M. Tourism space in developing countries. Annals Tourism Research. vol.20, n. ${ }^{\circ} 4$, pp.535-556, 1993.

PALMER, A.; BEJOU, D. Tourism destination marketing alliances. Annals of Tourism Research. vol.22, n. ${ }^{\circ 3}$. pp.616-629, 1995.

PARKER, S. Collaboration on tourism policy making: environmental and comercial sustainability on Bonaire, NA. In BRAMWELL, B. \& LANE, B. (Eds). Tourism collaboration and partnerships - politics, practice and sustainability. Clevedon: Chanel View Publications, 2000.

PEARCE, D. Tourism Development. London: Longman, 1989.

PELLIN, V. O turismo no espaço rural como alternativa para o desenvolvimento local sustentável: o caso do Município de Rio dos Cedros, Caderno Virtual de Turismo, vol.5, n. ${ }^{\circ} 1$, 2005. http://www.inclusaodejovens.org.br/Documentos/BIBLIOTECA/Desenvolvimento/ turismo_como_alternativa.pdf. Acesso em: 2 de mar 2010.

RHODES, R. The new governance: governing without government. Political Studies. XLIV, pp.652-667, 1996.

RIBEIRO, J.; VAREIRO, L. Turismo e desenvolvimento regional: o espaço rural como destino turístico. In Atas do 1. ${ }^{\circ}$ Congresso Internacional Casa Nobre, Universidade do Minho, 2007. http://www3.eeg.uminho.pt/economia/nipe/docs/Publicacoes_Actas_conferencias/2007/ Ribeiro_Laurentina_2007_AV.pdf. Acesso em: 29 jul 2012.

SELIN, S. Developing a typology of sustainable tourism partnerships. Journal of Sustainable Tourism, vol.7, n. ${ }^{\circ 3}$, 260-283, 1999.

SELIN, S.; BEASON, K. Inter-organizational relations in tourism. Annals of Tourism Research. vol.18, n. ${ }^{\circ 4}$, pp.639-652, 1991.

SHARPLEY, R. Managing the countryside for tourism: a governance perspective. In PENDER, L.; SHARPLEY, R. (Eds.). The Management of Tourism. London: Sage Publications, 2005.

SHARPLEY, R.; TELFER, D. Tourism and development - concepts and issues. Clevedon: Library of Congress Cataloging in Publication Data, 2002.

SHEEHAN, L.; RITCHIE, J. R. Destination stakeholders exploring identity and salience. Annals of Tourism Research, vol.32, n. ${ }^{\circ 3}$, pp.711-734, 2005.

SILVA, J. A dimensão territorial no planejamento do desenvolvimento turístico no Brasil: modelo do pólo de crescimento x modelo territorialista e endógeno. Revista Turismo em Análise, São Paulo, 17 (n. ${ }^{\circ}$ especial). pp.5-23, 2006. 
SILVA, J.; PERNA, F. Turismo e desenvolvimento auto-sustentado. In COSTA, J. (Coord.). Compêndio de Economia Regional, APDR: Coimbra, 2002.

SILVA, J.; SILVA, J. Inserção territorial das actividades turísticas em Portugal: uma tipologia de caracterização. Revista Portuguesa de Estudos Regionais. n. ${ }^{\circ} 1$, pp.53-73, 2003.

SOUSA, L. Turismo e desenvolvimento local sustentável. Paraíba: EUMED, 2006.

TELFER, D.; SHARPLEY, R. Tourism and development in the developing world. Oxon: Routledge, 2008.

TIMOTHY, D. Cross-border partnership in tourism resource management international parks along the US-Canada border. Journal of Sustainable Tourism. vol.7, n. ${ }^{03 / 4}$, pp.182-205, 1999.

TIMOTHY, D. Cooperative tourism planning in a developing destination. Journal of Sustainable Tourism. vol.6, n.1, pp.52-68, 1998.

WALIGO, V.; CLARKE, J.; HAWKINS, R. Embedding stakeholders in sustainable tourism strategies. Annals Tourism Research, vol.55, pp.90-93, 2015.

WOOD, D.; GRAY, B. Towards a comprehensive theory of collaboration. The Journal of Applied Behavioral Science. N. ${ }^{\circ 27}$, pp.139-162, 1991.

ZHANG, H.; YAN, Y.; LO, K. The faciliting and inhibiting factors in cooperative tourism development of the Grater Pearl River Delta (GPRD), China. Journal of Quality Assurance in Hospitality \& Tourism. vol.10, n. 2, pp.139-152. 2009.

NOTAS

1 Nomenclatura Unidade Territorial - NUT

2 TER = Turismo em espaço rural (inclui agroturismo, casas de campo, hotéis rurais, outros TER); TH = Turismo de Habitação 